\title{
Cholesterol Oxidation by Soil Actinomycetes
}

\author{
By R. L. BROWN* aNd G. E. PETERSON \\ Department of Biology, University of Houston, Houston, Texas, U.S.A.
}

(Received 28 March 1966)

\section{SUMMARY}

Cholesterol enrichment cultures from soil samples yielded various Nocardia and Streptomyces spp. capable of metabolizing cholesterol aerobically as a sole carbon source. One of these isolates, designated Streptomyces $14 \mathrm{PH} 8$, formed haloes (cholesterol-free zones surrounding colonies) on cholesterol mineral salts agar. This organism was selected for further study as it was able to utilize $80-100 \%$ of $0 \cdot 1 \%(\mathrm{w} / \mathrm{v})$ cholesterol in a mineral salts medium in 6 days. Oxidation of the sterol was initiated by a cholesterol dehydrogenase, giving 4-cholestene-3-one. The latter compound was then hydroxylated to form 4-cholestene-4-ol-3-one. Isotopic tracer studies revealed all of carbon-4 and most of carbon-26 of cholesterol were converted to ${ }^{14} \mathrm{CO}_{2}$. However, some of carbon-26 was converted to cell material.

Streptomyces I4PH8 gave several variants, one of which (Streptomyces I4PH8 no. 2 var. A) could be reclassified as a Nocardia, using the same method of Gordon \& Smith (1955).

\section{INTRODUCTION}

In 1913 Sohngen first reported growth of soil micro-organisms in a cholesterol medium. Haag (1927) then demonstrated cholesterol utilization by a soil mycobacterium. Both these investigators used growth as the sole criterion of cholesterol utilization. It remained for Tak (1942) to show chemical evidence that a soil mycobacterium was actually metabolizing the sterol. Turfitt $(1943,1944,1948)$ investigated microbial metabolism of cholesterol using Nocardia erythropolis, demonstrating metabolic changes in a cholesterol containing medium, as well as several intermediary metabolites of cholesterol degradation. Several other investigators have shown results similar to those of Turfitt (Kramli \& Horvath, 1947; Schatz, Savard \& Pintner, 1949; Arnaudi, 1951, 1954; Stadtman, Cherkes \& Anfinson, 1954).

By cholesterol enrichment techniques Lewis (1962) isolated several streptomycetes which could utilize cholesterol as a sole carbon source. These micro-organisms were more efficient at degrading cholesterol than any described in the papers above, degrading some $80 \mathrm{mg}$. cholesterol in only 6 days.

Using certain metabolic inhibitors, Whitmarsh (1964) demonstrated several intermediate metabolites not previously known.

This paper is meant to be an extension of the work on the catabolism of cholesterol by micro-organisms. Evidence is presented for the metabolism of cholesterol as a sole carbon source by several streptomycetes.

* Present address: Department of Microbiology, The University of Texas Medical Branch, Galveston, Texas. 


\section{METHODS}

Media. The composition of the mineral salts culture solution, as described by Turfitt (1948), was as follows (g./l.); $\mathrm{KNO}_{3}, 2 \cdot 0 ; \mathrm{K}_{2} \mathrm{HPO}_{4}, 0.25 ; \mathrm{MgSO}_{4} .7 \mathrm{H}_{2} \mathrm{O}$, $0.25 ; \mathrm{NaCl}, 0.005 ; \mathrm{FeSO}_{4} .7 \mathrm{H}_{2} \mathrm{O}, 0.0001$; agar (where used), 15; made up in tap water, 1 l.; adjusted to $\mathrm{pH} 7 \cdot 0$.

Cholesterol mineral salts agar was prepared by using the dispersion technique of Peterson, Lewis \& Davis (1962). Cholesterol was always sterilized separately from the aqueous medium, since it has been shown that the sterol undergoes auto-oxidation when treated in aqueous media (Peterson et al. 1962).

Organisms. Organisms were obtained from soil samples as follows: samples of soil $(5 \mathrm{~g}$.) were washed with $10 \mathrm{ml}$. sterile tap water, centrifuged, and the precipitate was poured into $50 \mathrm{ml}$. cholesterol mineral salts medium. This was incubated at $27^{\circ}$ on a rotary shaker at $180 \mathrm{rev} . / \mathrm{min}$. After incubation for 6 days, $0 \cdot 1 \mathrm{ml}$. samples were removed and streaked on several cholesterol mineral salts agar plates, which were incubated at $27^{\circ}$ for 6 days. Isolated colonies were then subcultured to purify and placed in stock cultures on tubes of the same type agar. These organisms were compared to stock cultures kept at this institution as to their cholesterol utilization and classification characteristics.

Growth. Inocula for metabolic experiments were prepared on plates containing mineral salts agar $\pm \mathbf{0} \cdot \mathbf{2} \%(\mathrm{w} / \mathrm{v})$ cholesterol. These were incubated for 6 days at $27^{\circ}$. The growth was then suspended in $24 \mathrm{ml}$. sterile tap water; $2 \mathrm{ml}$. of this suspension was used to inoculate each metabolism flask.

Metabolism flasks were made by aseptically transferring $50 \mathrm{ml}$. sterile mineral salts solution to $250 \mathrm{ml}$. Erlenmeyer flasks containing $50 \mathrm{mg}$. sterile cholesterol. The metabolism flasks were incubated on a rotary shaker at $27^{\circ}$ and $180 \mathrm{rev} . / \mathrm{min}$. Duplicate flasks were sampled at 0, 1, 2, 4 and 6 days of incubation. At the time of removal, the contents of each flask were extracted with $25 \mathrm{ml}$. chloroform. The chloroform and aqueous layers were separated and stored at $4^{\circ}$ until analysed.

Cholesterol and 4-cholestene-3-one determinations. Cholesterol was determined by the Sperry \& Webb (1950) modification of the Lieberman-Burchard reaction.

4-Cholestene-3-one was determined by the method of Stadtman et al. (1954) for detecting phenylhydrazone derivatives.

Classification of organisms. Classification of organisms under study was accomplished by the method of Gordon \& Smith (1955).

Isotopic tracer studies. Twenty-five $\mu \mathrm{c}$ of $4-{ }^{14} \mathrm{C}$-cholesterol were added to a Waring blendor containing $300 \mathrm{ml}$. of sterile mineral salts solution and blended for $2 \mathrm{~min}$. This was repeated in another blendor flask but with $26-{ }^{14} \mathrm{C}$-cholesterol. The content of each blendor were poured into a separate, stoppered, $50 \mathrm{ml}$. metabolism flask and inoculated with aerial mycelia washed from two 6-day Kollé plates containing $0 \cdot 2 \%(\mathrm{w} / \mathrm{v})$ cholesterol mineral salts agar. Metabolism was allowed to proceed at $27^{\circ}$. A constant supply of sterile air was bubbled into the flasks at $5 \mathrm{lb}$./in. ${ }^{2}$. Output $\mathrm{CO}_{2}$, produced by biological activity, was trapped in an attached small flask which contained $150 \mathrm{ml} .0 \cdot 1 \mathrm{~N}-\mathrm{NaOH}$. At $24 \mathrm{hr}$ intervals, $10 \mathrm{ml}$. samples were removed from each of the metabolism flasks and extracted with $5 \mathrm{ml}$. chloroform. Two $\mathrm{ml}$. of each of the chloroform extracts were placed in separate deep planchettes (2 ml.) and counted, after being dried, for 5 min. on a Nuclear Chicago Model $181 \mathrm{~A}$ 
counter. At the same time, $5 \mathrm{ml}$. of the $\mathrm{NaOH}$ solution was removed, precipitated with $5 \mathrm{ml} . \mathbf{0} \cdot 1 \mathrm{M}-\mathrm{BaCl}_{2}$, and the precipitate collected on a sintered steel filter containing a uniform layer of $6 \mathrm{mg}$. Celite; these were dried and counted as just described. The organisms were filtered, washed with chloroform, dried and counted in planchettes as described for the carbonate collection. The cell-free aqueous layers were treated and counted as described in the procedure for the chloroform extracts.

Identification of 4-cholestene-4-ol-3-one. The presence of 4-cholestene-4-ol-3-one was ascertained by chromatography, absorption spectra, and melting-point determinations as described below. Ultraviolet absorption spectra were determined by evaporating $25 \mathrm{ml}$. of the chloroform extract from pooled metabolism flasks, dissolving the residue in ethanol, and obtaining the spectrum on a Beckman Model DB spectrophotometer. Chromatograms were made by using Silica gel $\mathbf{H}$ (250 $\mu$ layers) developed with solvents $9+1(\mathrm{w} / \mathrm{v})$ benzene ethanol (Randerath, 1963) and a $4+1$ chloroform ethyl acetate (Bennet \& Heftman, 1962). The functional hydroxyl group was detected by using a $5 \%$ (w/v) phosphomolybdic acid (in absolute ethanol) spray reagent; the ketone group was detected by using a phenylhydrazine spray reagent. Melting points were determined by adding $1 \%(\mathrm{w} / \mathrm{v})$ digitonin (in ethanol) and allowing the mixture to stand for $18 \mathrm{hr}$. The digitonides were collected by centrifugation and added to $25 \mathrm{ml}$. pyridine and extracted with ether. This extract was streaked in a solid line across the bottom of a Silica gel G plate (250 $\mu$ layer) and developed to the $10 \mathrm{~cm}$. mark with the $4+1$ (by vol.) chloroform ethyl acetate solvent. The area around $R_{F} 0.97$ was scraped from the plate, taken up in chloroform, and filtered free from Silica gel. After drying, the melting point of the resulting crystals was taken on a Fisher melting-point apparatus.

The synthesis of 4-cholestene-4-ol-3-one was by the method of Fieser (1954).

Cholesterol dehydrogenase. Studies of the enzyme cholesterol dehydrogenase, first shown in these organisms by Davis, Brown, Lewis \& Peterson (1964), were made by filtering $250 \mathrm{ml}$. of 6 -day metabolism liquor through sintered glass filters. Twentyfive $\mathrm{ml}$. of this cell-free liquor was then inoculated into each of six $250 \mathrm{ml}$. Erlenmeyer flasks, each containing $10 \mathrm{mg}$. sterile cholesterol. These flasks were incubated at $27^{\circ}$ and $180 \mathrm{rev} . / \mathrm{min}$. on a rotary shaker. Two flasks were removed at 0 , two at 3 days, and two at 6 days. The contents of each flask were extracted with $10 \mathrm{ml}$. chloroform. After separation, the layers were stored at $4^{\circ}$ until all flasks had been removed, at which time all flasks were assayed for cholesterol and 4-cholestene-

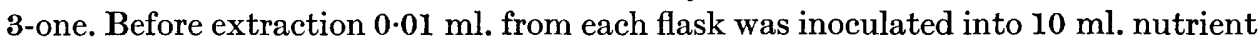
broth, allowed to incubate at $27^{\circ}$ for 3 days, and observed for growth. The appearance of turbidity was taken to indicate that the enzyme preparations contained viable organisms. These, where found, were discarded.

\section{RESULTS}

The metabolism of cholesterol by soil actinomycetes is shown in Figs. 1 and 2. A comparison is shown between streptomycetes and nocardias.

Classification of organisms. The results of the classification studies are shown in Table 1. Comparisons are shown to known stock cultures kept at this institution. Streptomyces K1PH7 and K2PH7 were found in soils near Kerrville, Texas, and the others were taken from the soil near Houston, Texas. Streptomyces I4PH8 no. 2 A 
was a variant obtained by serial enrichment culture of the parent isolate I4PH8 on cholesterol mineral salts medium. Serial transfers of Streptomyces I4PH8 at weekly intervals to fresh cholesterol mineral salts medium were made for a period of several

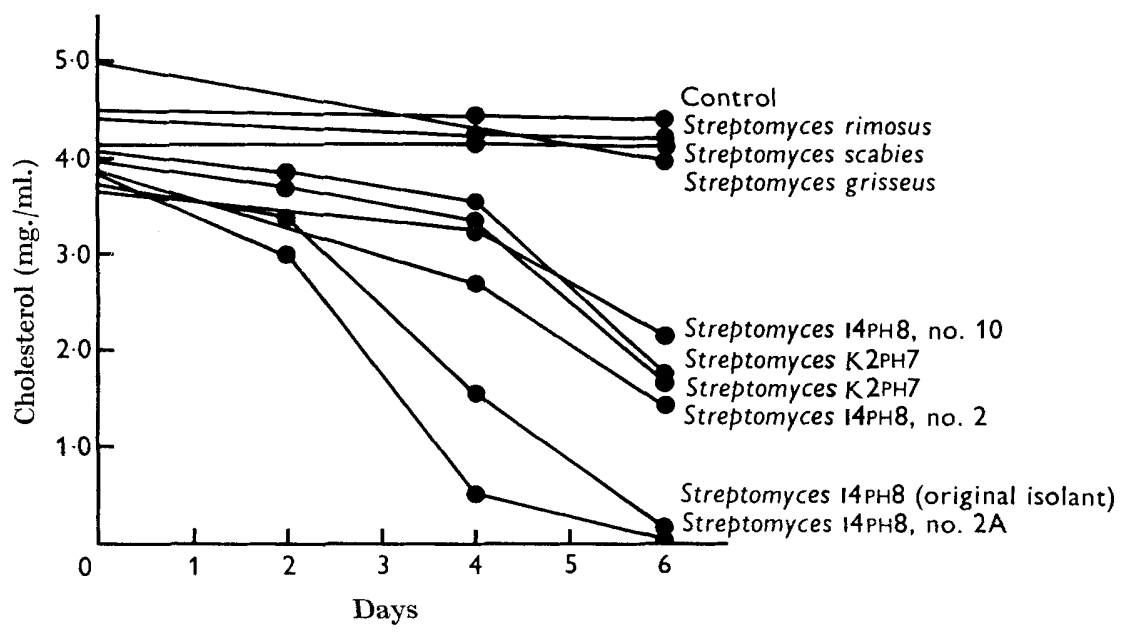

Fig. 1. Metabolism of cholesterol by various streptomyces species.

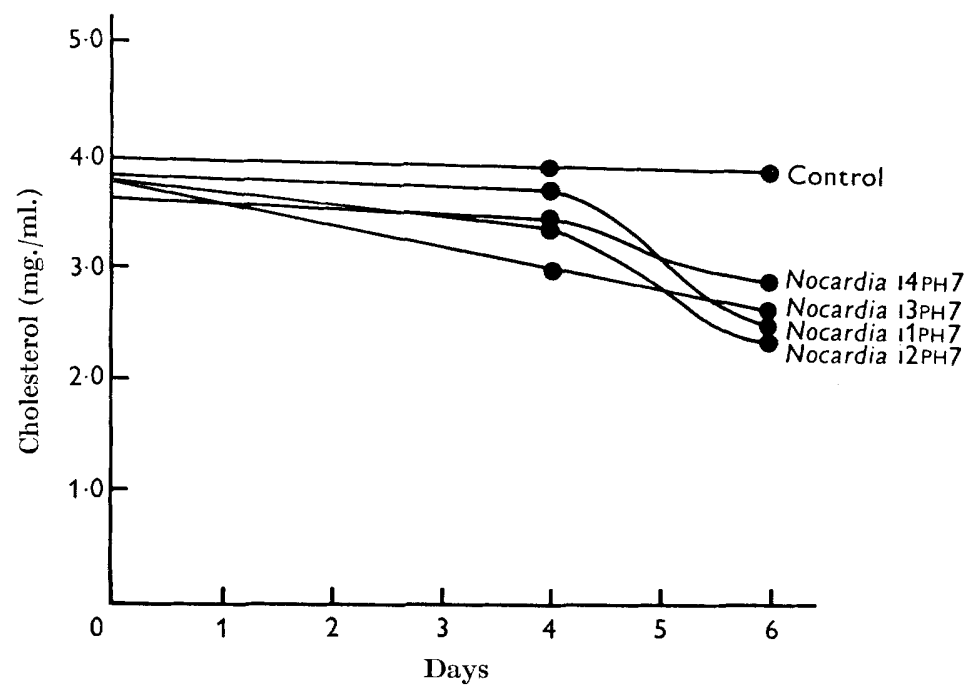

Fig. 2. Metabolism of cholesterol by various nocardia species.

months. At this time the organism used more cholesterol than ever before, but its biochemical and morphological characteristics had changed. It now grew only very sparsely on cholesterol mineral salts agar, although growth in liquid cholesterol medium and output of cholesterol dehydrogenase was greatly enhanced. Further, according to the same procedure of Gordon \& Smith (1955), it now more nearly resembles a nocardia.

The metabolic changes wrought by the action of Streptomyces I4PH8 on chol- 


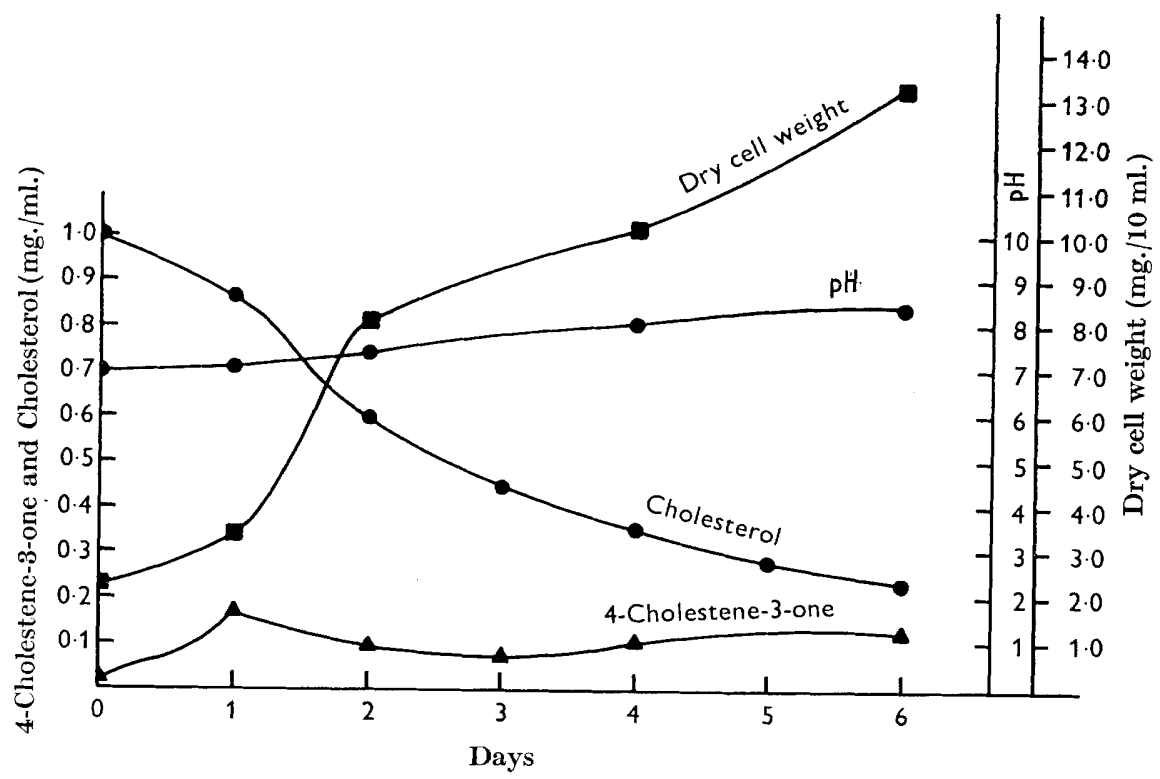

Fig. 3. Biochemical changes occurring in cholesterol mineral salts liquor as a result of growth of Streptomyces I4PH 8.

Table 1. Characteristics of soil isolates according to the procedure of Gordon \& Smith (1955)

\begin{tabular}{|c|c|c|c|c|c|c|c|c|c|c|}
\hline & $\begin{array}{l}\text { Lect- } \\
\text { ose }\end{array}$ & $\begin{array}{l}\text { Malt- } \\
\text { ose }\end{array}$ & $\begin{array}{l}\text { Xyl- } \\
\text { ose }\end{array}$ & $\begin{array}{l}\text { Mann- } \\
\text { ose }\end{array}$ & $\begin{array}{l}\text { Decom- } \\
\text { position } \\
\text { of tyro- } \\
\text { sine }\end{array}$ & $\begin{array}{l}\text { Hydro- } \\
\text { lysis of } \\
\text { casein }\end{array}$ & $\begin{array}{l}\text { Aerial } \\
\text { mycelia }\end{array}$ & Spores & $\begin{array}{l}\text { Acid } \\
\text { fast- } \\
\text { ness }\end{array}$ & $\begin{array}{c}\text { Halo } \\
\text { forma- } \\
\text { tion }\end{array}$ \\
\hline $\begin{array}{l}\text { Streptomyces } \\
\text { I4PH } 8\end{array}$ & $A^{*}$ & $A$ & A & $\mathbf{A}$ & + & + & + & + & + & + \\
\hline $\begin{array}{l}\text { Streptomyces } \\
\text { I4PH } 8 \text { no. } 2\end{array}$ & $\mathbf{A}$ & $A$ & $\mathbf{A}$ & A & + & - & - & Sli. $\dagger$ & - & + \\
\hline $\begin{array}{l}\text { Streptomyces } \\
\text { I4PH } S \text { no. } 10\end{array}$ & A & A & - & A & + & - & Decr. & + & - & - \\
\hline $\begin{array}{l}\text { Streptomyces } \\
\text { I } 4 \mathrm{PH} 8 \text { no. } 2 \\
\text { var. A }\end{array}$ & - & - & - & A & + & - & - & - & - & - \\
\hline $\begin{array}{l}\text { Nocardia } \\
\text { IlPH } 7\end{array}$ & - & - & - & - & - & - & + & + & - & - \\
\hline $\begin{array}{l}\text { Nocardia } \\
\text { I2PE } 7\end{array}$ & - & - & A & - & - & - & + & + & - & - \\
\hline $\begin{array}{l}\text { Nocardia } \\
\text { 13PH } 7\end{array}$ & - & - & - & A & + & - & Rud.\$ & - & $\mathrm{SI} . \|$ & - \\
\hline $\begin{array}{l}\text { Nocardia } \\
\text { I4PH } 7\end{array}$ & - & - & - & - & - & - & + & + & - & - \\
\hline $\begin{array}{l}\text { Streptomyces } \\
\text { K1PH } 7\end{array}$ & - & $A$ & - & A & + & - & + & + & - & - \\
\hline $\begin{array}{l}\text { Streptomyces } \\
\text { к2PII } 7\end{array}$ & A & A & - & $A$ & + & - & + & + & Sl. & - \\
\hline $\begin{array}{l}\text { Streptomyces } \\
13 \mathrm{PH} 4\end{array}$ & $\mathbf{A}$ & A & A & A & + & - & + & + & + & - \\
\hline
\end{tabular}

$* \mathrm{~A}=$ acid. $\quad$ Sli. $=$ slime former. $\quad$ + Decr. $=$ decreased. $\quad \|$ Sl. $=$ slight.
$\$$ Rud. = rudimentary.

Halo formation was not included in the method of Gordon \& Smith (1955). 


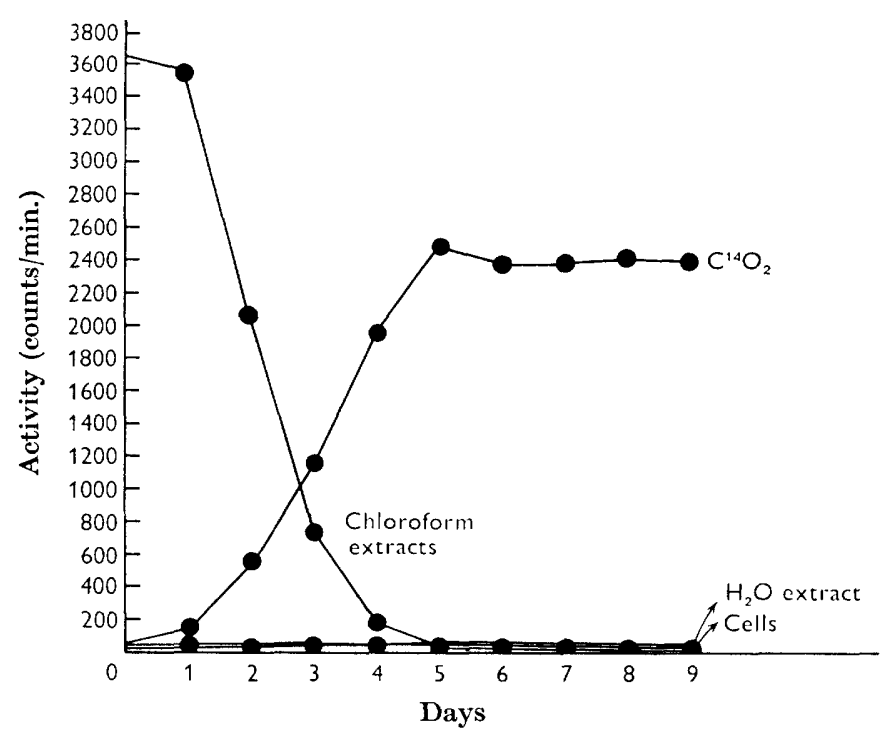

Fig. 4. Distribution of activity of $26-{ }^{14} \mathrm{C}$-cholesterol as a result of growth of Streptomyces i4pH8 no. 2.

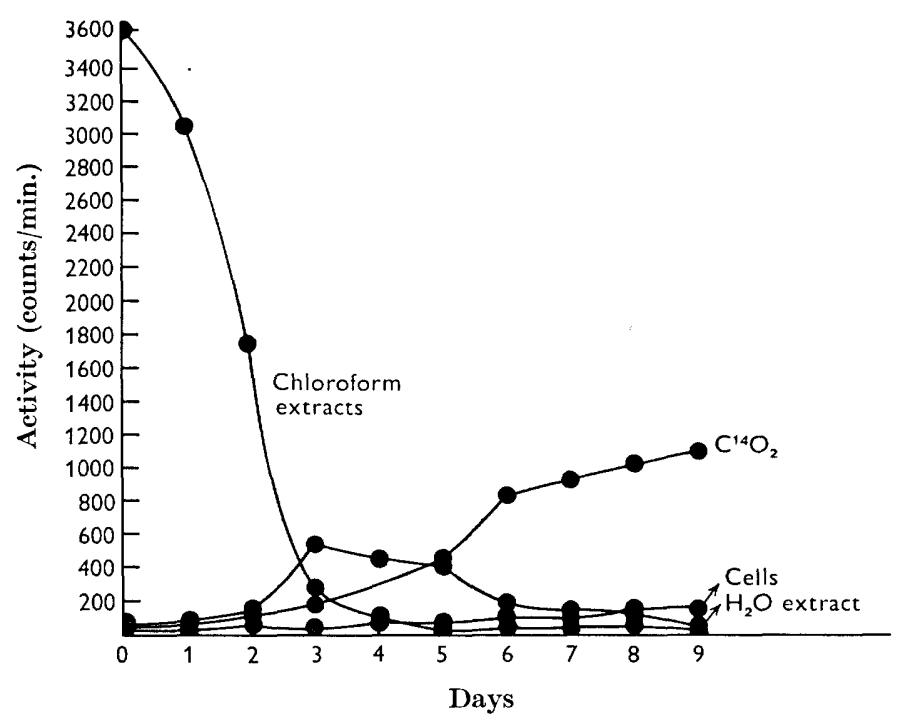

Fig. 5. Distribution of activity of $4^{-14} \mathrm{C}$-cholesterol as a result of growth of Streptomyces I4PH 8 no. 2.

Table 2. Oxidation of cholesterol by cell-free extracts of Streptomyces ${ }_{14} 4 \mathrm{PH}$ no. 2 var. $A$

\section{Days of} incubation

0

3
Residual cholesterol (mg./ml.)

$0 \cdot 441$

$0 \cdot 345$

$0 \cdot 295$ 4-cholestene-3-one produced (mg./ml.)
0 $0 \cdot 231$ 
esterol are shown in Fig. 3. The decrease in cholesterol content of the medium was accompanied by a corresponding increase in the amount of 4-cholestene-3-one, which was further metabolized to cell material.

Cholesterol dehydrogenase. The activity of the enzyme cholesterol dehydrogenase is depicted in Table 2. The amount of 4-cholestene-3-one produced was, within experimental limits, equal to the amount of cholesterol degraded.
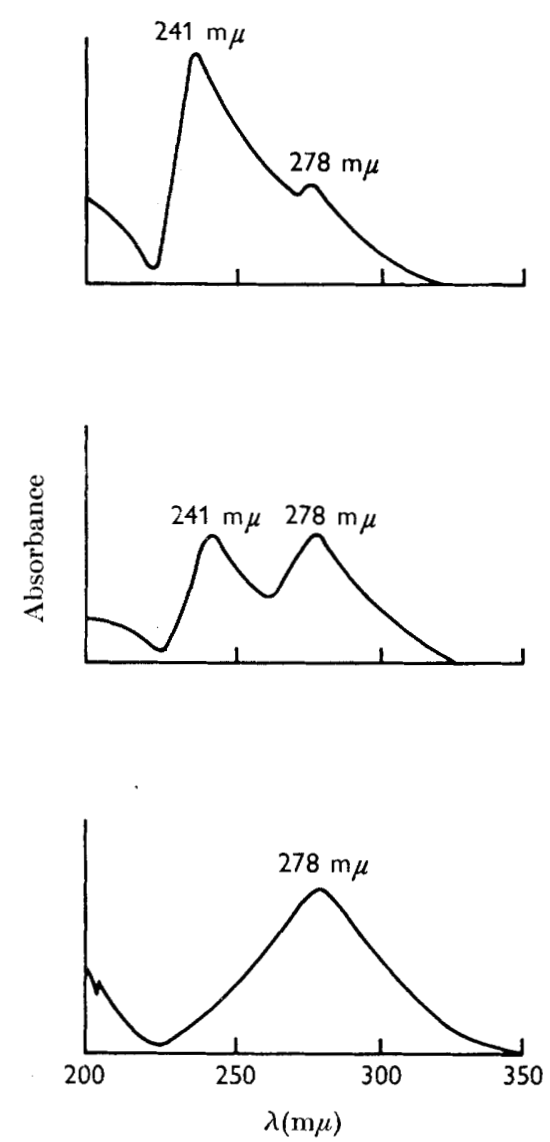

Fig. 6. Ultraviolet absorption spectra. Top: chloroform extract of cholesterol mineral salts liquor after 6-day incubation with Streptomyces I4PH 8 no. 2. Centre: a 1/10 dilution of the same extract, with added 4-cholestene-4-ol-3-one. Bottom: spectrum of pure 4-cholestene-4-ol-3-one.

Isotopic tracer studies. Figures 4 and 5 show the radioactivity of both $4^{-14} \mathrm{C}$ -

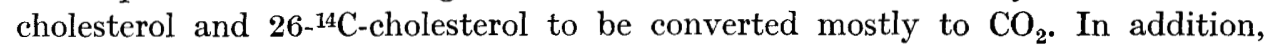
${ }^{26}{ }^{14} \mathrm{C}$-cholesterol was also metabolized to some water soluble component as well as to cell components.

Identification of 4-cholestene-3-one and 4-cholestene-4-ol-3-one. Ultraviolet absorption spectra are shown in Fig. 6, which shows the spectra of 4-cholestene-4-ol-3-one, a suspected intermediate, and a mixture of the two, indicating identical absorption maxima. The suspected intermediate had a melting point of $150 \cdot 5^{\circ}$, which is compatible with authentic 4-cholestene-4-ol-3-one. 
Table 3 shows thin layer chromatographic comparisons of 6-day metabolism extracts with 4-cholestene-3-one and 4-cholestene-4-ol-3-one. The extracts show spots compatible with the two standards used. One intermediate, 4-cholestene-3-one, contains a ketone group and absorbs u.v. radiation maximally at $241 \mathrm{~m} \mu$. The second intermediate, suspected of being 4-cholestene-4-ol-3-one, contains both a ketone and a hydroxyl group and has the same $\boldsymbol{R}_{f}$ values as does the known compound. The ketone group was shown by the use of a phenylhydrazine spray reagent, and the hydroxyl function showed bright blue when sprayed with a $5 \%(\mathrm{w} / \mathrm{v})$ phosphomolybdic acid solution.

Table 3. Thin layer chromatograms of 6-day fermentation extracts of Streptomyces 14 PH 8 grown on cholesterol-mineral salts broth

\begin{tabular}{|c|c|c|c|c|c|c|c|}
\hline \multicolumn{8}{|c|}{$\boldsymbol{R}_{F}$} \\
\hline \multicolumn{2}{|c|}{ Extracts } & \multicolumn{2}{|c|}{ Cholesterol } & \multicolumn{2}{|c|}{ 4-cholestene-3-one } & \multicolumn{2}{|c|}{$\begin{array}{l}\text { 4-cholestene- } \\
\text { 4-ol-3-one }\end{array}$} \\
\hline $1^{*}$ & $2 \dagger$ & $1 *$ & $2 \dagger$ & $1^{*}$ & $2 \dagger$ & $1 *$ & $2 \dagger$ \\
\hline 0.76 & 0.93 & . & . & . & 0.95 & $0 \cdot 75$ & 0.95 \\
\hline $0 \cdot 52$ & $0 \cdot 67$ & . & $0 \cdot 65$ & $0 \cdot 50$ & - & . & . \\
\hline $0 \cdot 25$ & . & $0 \cdot 25$ & . & - & - & - & . \\
\hline
\end{tabular}

\section{DISCUSSION}

From the data presented, it can be seen that carbon- 4 and carbon- 26 were both decarboxylated, with carbon-4 going entirely to $\mathrm{CO}_{2}$ and carbon-26 being at least partially taken into cell components. Further tracer studies, which would allow us to determine the fate of other carbons, were hampered by the unavailability of other ${ }^{14} \mathrm{C}$-labelled compounds.

The pathway by which isolate I4PH8 breaks down the cholesterol molecule is apparently begun by oxidation of the molecule to 4-cholestene-3-one. This in turn hydroxylated at 4-carbon position to give 4-cholestene-4-ol-3-one, which is further metabolized by decarboxylation. No other intermediates have as yet been found. In view of this 4-carbon decarboxylation, one might postulate a link between similar species of micro-organisms, such as the similarity between the organism used at this institution and the Nocardia erythropolis of Turfitt (1948). In addition, there is also some similarity to the Mycobacteria of Stadtman et al. (1954). This organism produced an extracellular cholesterol dehydrogenase which degraded cholesterol to 4-cholestene-3-one. This was then degraded via loss of carbon-4 and carbon-26; all of these reactions are in common with those found at this institution. Among other compounds, Turfitt found his Nocardia to produce Windaus's keto acid, which could result from decarboxylation of 4-cholestene-4-ol-3-one. A likely mechanism could be a CD2-A decarboxylation of Diels's acid, or, less likely, dihydro Diels's acid.

Cholesterol dehydrogenase from Streptomyces I4PH8 no. 2 converted some $37 \%$ of the cholesterol sample to cholestenone in cell-free extracts with a corresponding (near-quantitative) increase in 4-cholestene-3-one. 
Problems continuously asserted themselves in the inherent instability of Streptomyces I4PH8. The parent strain gave two variants, Streptompces I4PH no. 2 and I4PH8 no. 10, which differed from the original isolate, as shown in Table 1 . The no. 2 strain retained its halo-forming ability but formed a slime on a more complete medium (such as Bennet's agar or tomato paste oatmeal agar). This was in contrast to the parent strain, which formed gray spores on the complete medium. Loss of the ability to form haloes was accompanied by a decrease in the amount of cholesterol the organism could metabolize. The exception to this is seen in Streptomyces I4PH8 no. $2 \mathrm{~A}$, which is by far the most active microorganism in our stocks on cholesterol-containing mineral salts medium. This variant not only did not form haloes, but grew only very sparsely on cholesterol mineral salts agar. Just why this is seen is unknown, but apparently the long-term enrichment culture used to attain this variant resulted in the selection of a particular strain (or heterocaryon) which grew better in liquid media than on solid media. This variant now resembles a Nocardia sp. more closely than the parent Streptomyces sp. This may indicate a closer link between the two groups than previously suspected.

This work was supported in part by the National Institutes of Health, Bethesda, Maryland, U.S.A., Grant no. AI-03037.

\section{REFERENCES}

Arnaudi, C. (1951). Oxydations du microbiennes des steroids. Experientia 5, 120.

Arnaudi, C. (1951). Research on the microbiological degradation of steroids. Appl. Microbiol 2, 274 .

Bennet, R. D. \& Heftman, E. (1962). 'Thin layer chromatography of corticosteroids. J. Chromatog. 9, 348.

Davis, J. R., Brown, R. L., Lewis, H. L. \& Peterson, G. E. (1964). Cholesterol utilization by Streptomyces spp. Bact. Proc. p. 100.

Fieser, L. G. \& Stevenson, R. (1954). Cholesterol and companions. Oxidation of 5cholestene-3-one with lead tetraacetate. J. Am. chem. Soc. 76, 1731.

Gordon, R. E. \& Sмiтh, M. M. (1955). A proposed group of characters for the separation of Streptomyces and Nocardia. J. Bact. 69, 147.

HaAG, F. (1927). Die saphrophytischen Mycobacterien. Zentbl. Bakt. ParasitKde Abt. II $71,1$.

Kramli, A. \& Honvath, J. (1947). Microbiological oxidation of cholesterol with Azotobacter. Nature, Lond. 160, 639.

LEwis, H. L. (1962). Evidence for cholesterol metabolism by soil streptomycetes. M.S. Thesis. University of Houston, Texas.

Peterson, G. E., Lewis, H. L. \& Davis, J. R. (1962). Preparation of uniform dispersions of cholesterol and other water insoluble carbon sources in agar media. J. lipid. Res. 3 275.

Peterson, G. E., Mandy, W. J., Futch, H. \& Luckey, D. (1962). Cholesterol deposition in Penicillium spp. Can. J. Microbiol. 8, 193.

Randerath, K. (1963). Thin Layer Chromatography. New York: Academic Press.

Schatz, A., Savard, K. \& Pintner, I.(1949). The ability of soilmicroorganisms to decompose cholesterol. J. Bact. 58, 117.

Söhngen, N. L. (1913). Benzin, Petroleum, Paraffinöl and Paraffin als Kohlenstoff-und Energiequelle für Mikroben. Zentbl. Bakt. ParasitKde (Abt. II), 37, 595.

Sperry, W. M. \& WebB, M. (1950). A revision of the Schoenheimer-Sperry method for cholesterol determination. J. biol. Chem. 187, 97.

Stadtman, T. C., Cherkes, A. \& Anfinson, C. B. (1954). Studies on the microbiological degradation of cholesterol. J. biol. Chem. 206, 511. 
Tak, J. D. (1942). On bacteria decomposing cholesterol. Antonie van Leeuwenhoek 8, 32. TurfitT, G. E. (1943). The microbiological degradation of steroids. I. The sterol content of soils. Biochem. I. 37, 115.

TurfitT, G. E. (1944). The microbiological degradation of steroids. II. Oxidation of cholesterol by Proactinomyces spp. Biochem. J. 38, 492.

TurfitT, G. E. (1948). Microbiological agencies in the degradation of steroids. II. Steroid utilization by the microflora of soils. J. Bact. 54, 557.

Whitmarsh, J. M. (1964). Intermediates of microbiological metabolism of cholesterol. Biochem. J. 90, 23 pp. 